\title{
Pseudascarophis brasiliensis sp. nov. (Nematoda: Cystidicolidae) parasitic in the Bermuda chub Kyphosus sectatrix (Perciformes: Kyphosidae) from southeastern Brazil
}

\author{
Felipe Bisaggio Pereira', Aldenice de Nazaré Pereira', Juan Tomás Timi², José Luis Luque ${ }^{1 /+}$ \\ ${ }^{1}$ Curso de Pós-Graduação em Ciências Veterinárias, Departamento de Parasitologia Animal, Universidade Federal Rural do Rio de Janeiro, \\ Seropédica, RJ, Brasil ${ }^{2}$ Laboratorio de Parasitología, Instituto de Investigaciones Marinas y Costeras, \\ Facultad de Ciencias Exactas y Naturales, Universidad Nacional de Mar del Plata, Mar del Plata, Argentina
}

A new species of Pseudascarophis (Nematoda: Cystidicolidae) found in the stomach of Kyphosus sectatrix (Linnaeus) (Kyphosidae), off Rio de Janeiro, Brazil, is described. The new species can be differentiated from the other congeners by the presence of lateral alae, distinct but inconspicuous cephalic papillae at the anterior end, three pairs of precloacal and one pair of adcloacal papillae in males, egg morphology and morphometry of glandular oesophagus and spicules. Pseudascarophis tropica is transferred to Ascarophis as Ascarophis tropica (Solov'eva) comb. n. due to its ambiguous diagnosis.

Key words: Cystidicolidae - Pseudascarophis - marine fish - Kyphosus - Rio de Janeiro - Brazil

During a parasitological survey, cystidicolid nematodes belonging to Pseudascarophis Ko, Margolis and Machida were recovered from stomachs of the Bermuda chub Kyphosus sectatrix (Linnaeus) (Kyphosidae) from the coastal zone of the state of Rio de Janeiro (RJ), Brazil. To date, there are three species of Pseudascarophis described, namely, Pseudascarophis genypteri Muñoz and George Nascimento, Pseudascarophis kyphosi Ko, Margolis and Machida and Pseudascarophis tropica Solov'eva, but none of them have been found in fishes from Brazil. One species is described from Japan, one from China and one from Chilean waters (Ko et al. 1985, Solov'eva 1996, Muñoz \& George-Nascimento 2001).

The present paper describes a new Pseudascarophis infecting $K$. sectatrix, a fish widely distributed in western Atlantic from Canada to Brazil, but also found in eastern Atlantic from South Morocco to the Gulf of Guinea and more rarely in Mediterranean and off Madeira (Froese $\&$ Pauly 2012). This fish inhabits shallow waters and is commonly found around coral reefs, feeding on benthic algae, small crabs and mollusks (Froese \& Pauly 2012).

\section{MATERIALS AND METHODS}

Six specimens of $K$. sectatrix (2 males with mean weigh of $950 \pm 50 \mathrm{~g}$, mean body length $376.5 \pm 30.4 \mathrm{~mm}$; 4 females with mean weigh of $868 \pm 146 \mathrm{~g}$, mean body

doi: 10.1590/0074-0276108042013013

Financial support: CONICET (PIP \# 112-200801-00024), ANPCYT (PICT \# 02199), UNMdP (EXA 531/10), CAPES, CNPq

FB was supported by a doctoral fellowship from CAPES, AP was supported by a doctoral fellowship from CNPq, JTT received financial support from CONICET and ANPCYT, JLL was supported by a research fellowship from CNPq.

+ Corresponding author: luqueufrrj@gmail.com

Received 13 September 2012

Accepted 18 December 2012 length $361.2 \pm 22.9 \mathrm{~mm}$ ) were caught by commercial trawlers in Angra dos Reis ( $23^{\circ} 00^{\prime} \mathrm{S} 44^{\circ} 10^{\prime} \mathrm{W}$ ), RJ. Fishes were kept in thermal boxes filled with ice prior to being transported to the laboratory and then immediately dissected. Both stomach and intestine were removed and examined individually using a stereoscopic microscope. Nematodes found were fixed in 95 parts of ethanol $70 \%$, three parts formaldehyde $40 \%$ and two parts of glacial acetic acid, cleared in lactophenol and studied and measured using light microscopy. For a detailed study of some structures, samples of eggs were extracted from a dissected uterus of a dissected female and the spicules were obtained from a dissected male. Drawings were made using a drawing tube attached to a light microscope Olympus BX 51, magnifications of 40X, 100X, 200X, 400X and 1000X.

For scanning electron microscopy (SEM), specimens were dehydrated in a series of ethanol washes, dried by evaporation with haexamethyldisilazane, coated with gold and scanned in a JEOL JSM 6460-LV SEM. The identification at the genus level was based on Moravec (2007) and Anderson et al. (2009) and ecological terminology follows that of Bush et al. (1997). Host identification was based on the illustrated key by Menezes and Figueiredo (1985); nomenclature and classification are updated according to FishBase (Froese \& Pauly 2012). The measurements are given in micrometers, except where otherwise stated. Mean values of measurements are followed by the range inside parentheses when convenient.

Holotype, allotype and paratypes are deposited in the Oswaldo Cruz Institute Helminthological Collection (CHIOC), RJ.

\section{RESULTS \\ Pseudascarophis brasiliensis sp. nov.} (Figs 1, 2)

Diagnosis - Females larger than males, anterior part of body more slender than posterior part; cuticle thick and transversely striated. Cephalic end rounded in both 
sexes, four submedian inconspicuous cephalic papillae, visible only by SEM (Fig. 2A, B) and pair of lateral amphids, posterolateral to pseudolabia (Fig. 2A). Oral aperture oval and dorsoventrally elongated; submedian labia and sublabia absent. Two lateral pseudolabia T-shaped in apical view, emerging externally and somewhat elevated in relation to lateral margins of oral aperture, arching medially to join lateral walls of anterior part of buccal cavity and lacking apical protrusions (Figs 1B, 2A, B). Four anteriorly directed tooth-like digitiform processes ( 2 subdorsal and 2 subventral), emerging sub-marginally from internal surface of oral cavity, not projecting beyond anterior margin of it (Figs 1B, 2A, B). Deirids bifurcated (Fig. 2C), slightly anterior to mid length of vestibule (Fig. 1A). Vestibule long, with distinct funnel-shaped prostom visible in lateral view (Fig. 1A). Glandular part of oesophagus very long, markedly longer than muscular portion. Nerve-ring encircles muscular oesophagus near its junction with vestibule, excretory pore slightly posterior to nerve ring (Fig. 1A). Narrow lateral alae present in both sexes (Fig. 2D, E), extending from level of prostom to that of anterior ends of subventral caudal alae in males and anterior to the level of anus in females.

Male (based on holotype and 9 paratypes) - Body 12.8 (10.3-15.4) $\mathrm{mm}$ long, maximum width at middle of body 82.5 (70-100); width at level of nerve ring 42.6 (3854), of oesophago-intestinal junction 55.8 (41-78) and of anus 59.6 (51-81). Height of pseudolabia 8 (7-9). Vestibule including prostom 136.4 (130-145) long; prostom 10 (8-12) long, 10.4 (8-12) wide in lateral view. Length of muscular oesophagus 330 (290-390); length of glandular oesophagus 5.5 (4.3-6.6) $\mathrm{mm}$; length ratio of muscular and glandular parts of oesophagus 1:16.6 (1: 14.4-21.47); length of entire oesophagus and vestibule representing
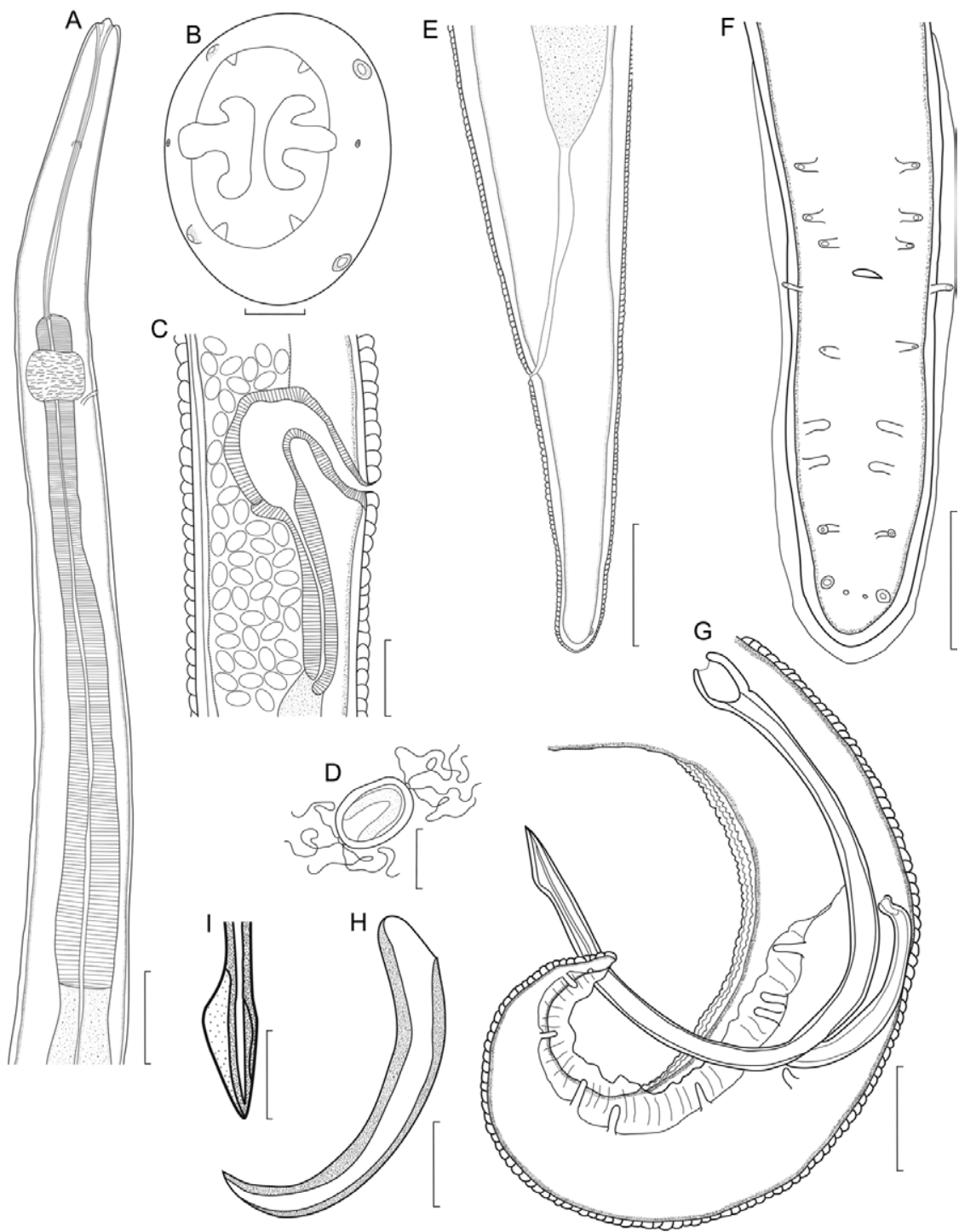

Fig. 1: line drawings of Pseudascarophis brasiliensis sp. nov. collected from the stomach of Kyphosus sectatrix from Rio de Janeiro, Brazil. A: anterior end of male, lateral view; B: cephalic end of female, apical view; C: region of vulva, lateral view; D: fully developed egg; E: posterior region of female, lateral view; F: posterior region of male, ventral view; G: posterior region of male, lateral view; H: right spicule, ventrolateral view; I: distal end of left spicule, ventrolateral view. Bars = A, C, G: $50 \mu \mathrm{m}$; B: $2 \mu \mathrm{m}$; D, H, I: $20 \mu \mathrm{m}$; E, F: $75 \mu \mathrm{m}$. 
$45.5(41-50) \%$ of total body length. Nerve-ring situated at 163.5 (140-180) from anterior extremity; deirids and excretory pore at 58 (50-65) and 180 (150-225), respectively, from anterior end. Posterior end of body spirally coiled provided with vesicular caudal alae (Figs $1 \mathrm{G}, 2 \mathrm{G}$ ). Ten pairs of caudal papillae. Pre-anal papillae: three pairs of subventral pedunculate papillae, of which second and third pairs close to each other (Fig. 1F). One pair of lateral pedunculate papillae somewhat posterior to cloacal aperture, which may occur at cloacal line. Postanal papillae: six pairs present, first four pairs subventral and pedunculate, fourth pair smaller than others, last two pairs sessile near tail tip, located at the same line, in which one is lateral and large and one ventral and very small where phasmidial openings are located (Fig. 1F). At least three longitudinal lines of serrate ventral cuticular ridges (area rugosa), anterior to cloaca, about 190 long (Figs 1G, 2H). Left spicule 380.6 (344-418) long, broad with circular rounded anterior end and somewhat inflated dorsoventrally at distal thin tip (Fig. 1I); its shaft 161 (145-178) long, forming 44.6 (2.1-46.3) \% of overall length of spicule (measured in 3 males). Right spicule 108.8 (100-116) long, stout with rounded distal end and thin tip (Fig. 1H). Length ratio of spicules 1:3.5 (3.1-4.1). Tail conical, 237 (200-280) long, with rounded tip.

Female (based on allotype and 9 paratypes, all gravid) - Body 17.7 (15.9-19.8) mm long; maximum width at middle of body 139.2 (100-190); width at level of nerve
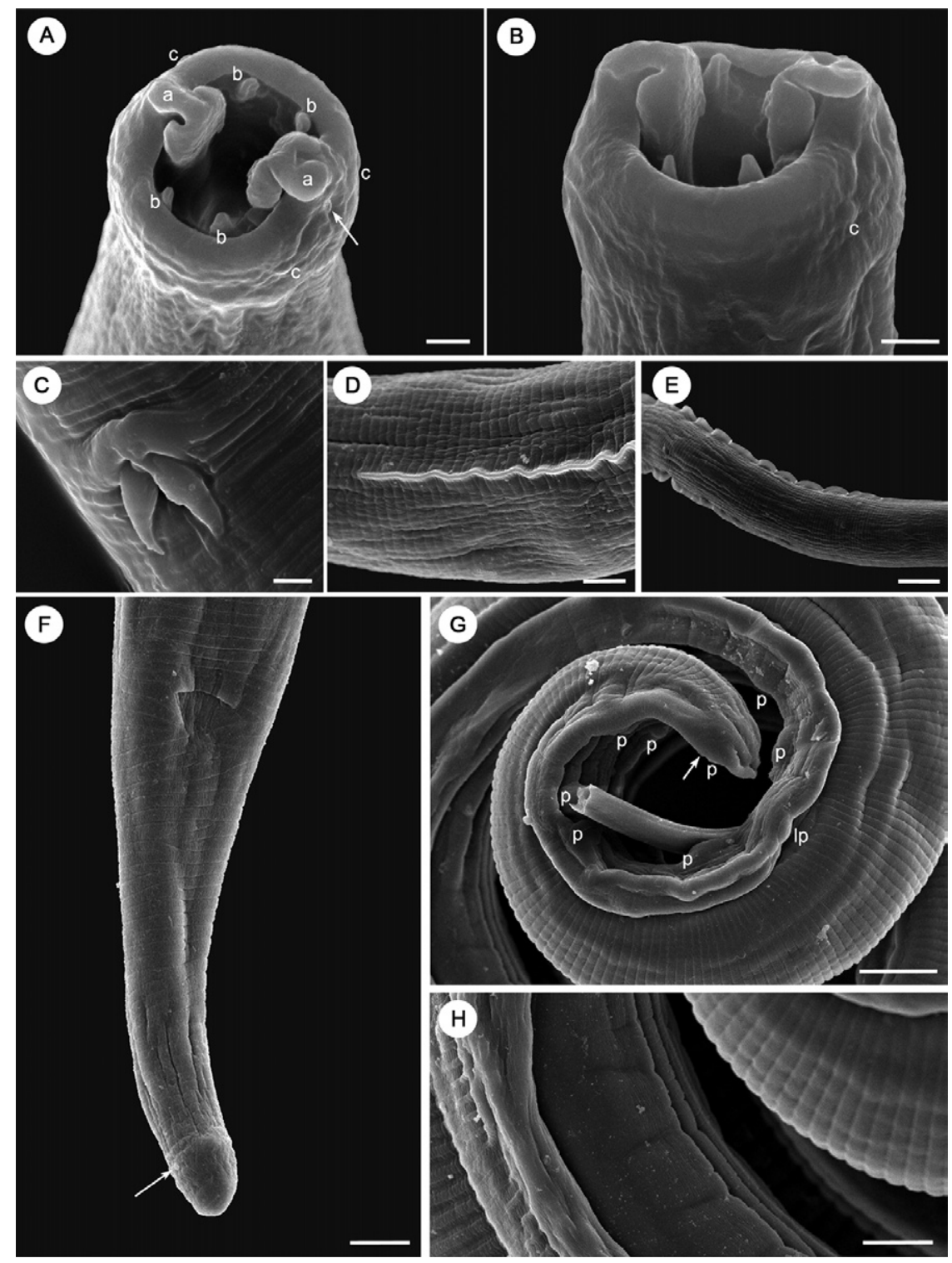

Fig. 2: scanning electron micrographs of Pseudascarophis brasiliensis sp. nov. collected from the stomach of Kyphosus sectatrix from Rio de Janeiro, Brazil. A: cephalic end, apical view (a: pseudolabia; b: tooth-like digitiform process; c: cephalic papillae; arrow head: amphid); B: cephalic end, ventrolateral view (c: cephalic papillae); C: deirid; D: lateral alae, lateral view; E: lateral alae, ventral view; F: posterior end of female, ventrolateral view (arrow head: phasmid); G: posterior end of male, lateral view (p: caudal papillae; lp: lateral caudal papillae; arrow head: phasmidial papilla); H: area rugosa of male. Bars =A, B, C: $2 \mu \mathrm{m}$; D: $5 \mu \mathrm{m}$; E, G: $20 \mu \mathrm{m} ; \mathrm{F}, \mathrm{H}: 10 \mu \mathrm{m}$. 
ring 46.9 (41-54), of oesophago-intestinal junction 64.7 (52-80) and of anus 66.5 (50-86). Height of pseudolabia 8.1 (6-9). Vestibule including prostom, 131.2 (110-143) long; prostom 12 (11-13) long, 10.4 (8-12) wide in lateral view. Length of muscular oesophagus 381.7 (300-465); length of glandular oesophagus 6.1 (5.3-6.7) mm; length ratio of muscular and glandular parts of oesophagus 1:16.1 (1:12.8-18.9); length of entire oesophagus and vestibule representing 36.4 (33-38)\% of total body length. Deirids, nerve-ring and excretory pore located at 61.2 (50-68), 152.5 (130-171) and 185.1 (149-220), respectively, from anterior extremity. Vulva posterior to middle of body, situated at $11.6(10.9-12.3) \mathrm{mm}$ from anterior end of body, at $65.8(60.1-70.5) \%$ of body length; vulvar lips not elevated (Fig.1C). Tail conical, 123.9 (110-150) long, with rounded tip (Figs 1E, 2F). Phasmidial opening in small lateral papillae about 10 from tail tip (Figs 1E, 2F). Amphidelphic, uterus occupying half of body, filled with numerous eggs. Mature eggs (containing larvae) oval, 31.1 (30-33) long and 20.9 (20-22) wide, thickwalled, with smooth surface and distinct polar knobs, one tuff of four thin filaments emerging from each polar knob (Fig. 1D).

Type host - K. sectatrix (Linnaeus) (Kyphosidae).

Site of infection - Stomach. RJ.

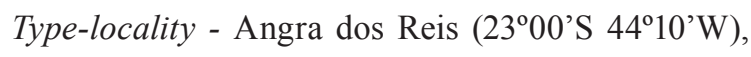

Type data and depository - Holotype (male specimen) CHIOC 35848a; allotype (female specimen) CHIOC 35848b; paratypes CHIOC 35849a (2 male specimens), CHIOC $35849 \mathrm{~b}$ (2 female specimens).

Host-parasite data - Prevalence: four infected fishes of six analysed; mean intensity of infection: $10 \pm 10.8$ (3-26); mean abundance: $6.7 \pm 9.8$.

Etymology - The specific name refers to the country where the specimens were collected.

\section{DISCUSSION}

The taxonomy and classification of Cystidicolidae has been complex because this group of nematodes exhibit small size; thus some of their morphologically important features are visible only by SEM (Moravec 2007, Moravec \& Justine 2010). Therefore, many of the previous studies lack morphological details and provide inadequate descriptions. Cephalic structures are generally considered to be important for the classification of Cystidicolidae, although their significance in generic discrimination is still under discussion and more evidence is necessary not only from electron microscopy, but also molecular data (Ferrer et al. 2005, Moravec et al. 2006, Moravec 2007, Moravec \& González-Solís 2007, Moravec \& Klimpel 2007, 2009). However, there is an increasing consensus in the literature for defining cystidicolid genera based on head morphology.

Several genera of Cystidicolidae (Ascarophis van Beneden, Caballeronema Margolis, Capillospirura Skryabin, Cystidicoloides Skinker, Pseudascarophis and Similascarophis Muñoz, González \& George-Nascimento) are very similar to each other, with minute differences represented by details of their cephalic structures, which are only visible by SEM. Moreover, there exist various intermediate features that can be interpreted as interspecific rather than intergeneric differences (Moravec \& Klimpel 2007). Indeed, many members of these genera have been reported within Ascarophis (Ferrer et al. 2005) or transferred to it (Moravec 2007, Moravec \& González-Solís 2007, Moravec \& Justine 2007). In fact, the latter authors have stated that it is apparent from SEM studies that the shape and size of pseudolabia, the shape of the mouth and the development of submedian labia (from well-developed to absent) may differ among Ascarophis species. Consequently, Ascarophis has been defined as a "catch all" genus, which also includes species with filamented and non-filamented eggs (Ferrer et al. 2005, Moravec 2007).

The general morphology of the new species agrees with most diagnostic features described for Pseudascarophis, which was erected to accommodate $P$. kyphosi, a parasite of the congeneric host Kyphosus cinerascens (Forskål) from Japan (Ko et al. 1985). Indeed, the structure of the mouth is almost identical between both species, indicating that the specimens studied here belong to Pseudascarophis, in agreement with Ko et al. (1985), as well as with the latest review of Cystidicolidae provided by Moravec (2007). The homogeneity of cephalic structures, therefore, confirms the validity of the genus Pseudascarophis.

The only discrepancies between the new species and the generic diagnosis provided by Ko et al. (1985) are the presence of lateral alae, cephalic papillae (referred as indistinct in the type species and consequently in the genus), three pairs of precloacal and one pair of adcloacal papillae in males (instead of only 3 pairs of precloacal and none adcloacal papillae) and the smooth egg shell instead of rugged shell as in P. kyphosi. The presence of four submedian cephalic papillae is a characteristic of spirurine nematodes (Moravec 2007) and these structures, apparently inconspicuous in $P$. kyphosi, probably were overlooked by Ko et al. (1985). The presence of lateral alae is an uncommon feature in cystidicollids, except for two genera, i.e., Ctenascarophis Mamaev and Metabronema (Taylor) (Crites et al. 1993, Moravec \& Justine 2007). Apparently, P. kyphosi lacks lateral alae, since these structures were not described by Ko et al. (1985), while in the new species it is clearly visualised. However, to be conclusive about the presence or absence of this feature in Pseudascarophis, the genus must be reviewed and all previous described species must be better studied, mainly because some of them (i.e., P. tropica and $P$. genypteri) seem to be misclassified.

Other differences between the new species and $P$. kyphosi are based on morphometry. Males of both species are similar in size, although the description of $P$. kyphosi is based on only two specimens. However, the new species has a longer glandular oesophagus (4.3-6.6 mm vs. 2.9-3.0 mm), a longer tail (200-280 vs. 125-150), longer spicules (left $344-418$ vs. $185-210$ and right $100-116$ vs. 80-90) and, as mentioned above, it has a different pattern of caudal papillae. Measurements of P. kyphosi females are also based on only two specimens, who are longer 
than the new species (27.2-33.4 mm vs. $15.0-19.8 \mathrm{~mm})$ and consequently all other measurements are larger. In addition, some morphometric relationships were different when comparisons were made after calculating some of these from the data provided by Ko et al. (1985). In fact, the new species has a relatively longer oesophagus (32.3$38.2 \%$ of body length vs. $23.3-28.3 \%)$ and tail ( $0.6-0.8 \%$ of body length vs. $0.4 \%$ ). Eggs of both species are similar in length, but those of $P$. kypsosi are thinner (14-17 vs. 20-22) and have more filaments (at least 6) in the tuffs of polar knobs, rather than four as in the new species.

At present, two other species have been described in Pseudascarophis, namely, P. tropica and P. genypteri (Solov'eva 1996, Muñoz \& George-Nascimento 2001). However, both of them have some features which differs them from the diagnosis of this genus, especially in the morphology of the cephalic end, casting doubts on their generic identity. In fact, the inclusion of P. tropica in Pseudascarophis is based on ambiguous diagnostic criteria such as "the structure of head end, digestive system and reproductive system" (Solov'eva 1996); although this species is described as having four teeth-like formations slightly protruded from outside of oral opening, but these structures are not depicted and specimens were not studied by SEM. On the other hand, the description of $P$. tropica suggests various similarities with $A s$ carophis parupenei Moravec, Orecchia and Paggi (e.g. morphology of cephalic end and posterior end of male, posterior extremity of female with a small appendix and non-filamented eggs) described from Parupeneus indicus (Shaw) (Mullidae) (Moravec et al. 1988), congeneric of Parupeneus chrysopleuron (Temminck \& Schlegel) which is the type host of $P$. tropica.

The other species, $P$. genypteri, a parasite of $\mathrm{Ge}$ nypterus chilensis (Guichenot) (Ophidiidae) from Chile (Muñoz \& George-Nascimento 2001), was originally assigned to this genus by lacking cephalic papillae, submedial and medial labia, as well as because of the progressive prominence of cuticular striations from anterior to posterior body regions and by having the anterior third of body wider than the posterior region. At specific level, $P$. genypteri was distinguished from $P$. kyphosi because it has larger spicules, rounded pseudolabia that join in the middle of the oral opening, eight digitiform buccal processes, unfilamented eggs and four pairs of preanal and five pairs of postanal papillae, the same set of differences allow distinguishing it from the new species. $P$. genypteri was considered different from Ascarophis by two characteristics, i.e., their pseudolabia appear to be rounded, instead of being conical as in Ascarophis and the anterior third is thicker than the rest of the body.

Therefore, for the time being, P. tropica is transferred to Ascarophis as Ascarophis tropica (Solov'eva) comb. n. by owing its ambiguous diagnosis, its similarity with $A$. parupenei and due to the broader spectrum of morphological features which this genus includes. On the other hand, $P$. genypteri is provisionally retained in Pseudascarophis, based on the criteria of Muñoz and GeorgeNascimento (2001) for separating it from Ascarophis and by the presence of digitiform buccal processes, until new evidence can help to clarify its generic status.

\section{REFERENCES}

Anderson RC, Chabaud AG, Willmot S 2009. CIH keys to the nematode parasites of vertebrates: archival Volume, Commonwealth Agricultural Bureaux, Farnham Royal, 480 pp.

Bush AO, Lafferty KD, Lotz JM, Shostak AW 1997. Parasitology meets ecology on its own terms: Margolis et al. revisited. J Parasitol 83: 575-583.

Crites JL, Overstreet RM, Maung M 1993. Ctenascarophis lesteri n. sp. and Prospinitectus exiguous n. sp. (Nematoda: Cystidicolidae) from the skipjack tuna Katsuwonus pelamis. J Parasitol 79: 847-859.

Ferrer E, Aznar FJ, Balbuena JA, Kostadinova A, Raga JA, Moravec F 2005. A new cystidicolid nematode from Mullus surmuletus (Perciformes: Mullidae) from the western Mediterranean. J Parasitol 91: $335-344$.

Froese R, Pauly D 2012. FishBase. [updated Aug 2012] [cited 15 Aug 2012]. Available from: fishbase.org/.

Ko RC, Margolis L, Machida M 1985. Pseudascarophis kyphosi n. gen., n. sp. (Nematoda: Cysticolidae) from the stomach of the fish Kyphosus cinerascens (Forskal) from Japan. Can J Zool 63: 2684-2688.

Menezes NA, Figueiredo JL 1985. Manual de peixes marinhos do Sudeste do Brasil. V. Teleostei (4), Museu de Zoologia da Universidade de São Paulo, São Paulo, 105 pp.

Moravec F 2007. Some aspects of the taxonomy and biology of adult spirurine nematodes parasitic in fishes: a review. Folia Parasitol 54: 239-257.

Moravec F, González-Solís D 2007. Structure of the cephalic end of Ascarophis mexicana (Nematoda: Cystilicolidae) as revealed by SEM. Folia Parasitol 54: 155-156.

Moravec F, Justine JL 2007. Redescription of Metabrenema magnum (Nematoda: Cystidicolidae), a swimbladder parasite of the carangid fish Gnathanodon speciosus off New Caledonia. Folia Parasitol 54: 293-300.

Moravec F, Justine JL 2010. Two new genera and species of cystidicolids (Nematoda, Cystidicolidae) from marine fishes off New Caledonia. Parasitol Int 59: 198-205.

Moravec F, Klimpel S 2007. A new species of Comephoronema (Nematoda: Cystidicollidae) from the stomach of the abyssal halosaur Halosauropsis macrochir (Teleostei) from the Mid-Atlantic Ridge. J Parasitol 93: 901-906.

Moravec F, Klimpel S 2009. Two new species of cystidicolid nematodes from the digestive tract of the deep-sea fish Coryphaenoides mediterraneus (Giglioli) (Macrouridae) from the MidAtlantic Ridge. Syst Parasitol 73: 37-47.

Moravec F, Klimpel S, Kara E 2006. Neoascarophis macrouri n. sp. (Nematoda: Cystilicolidae) from the stomach of Macrourus berglax (Macrouridae) in the eastern Greenland Sea. Syst Parasitol 63: 231-237.

Moravec F, Orecchia P, Paggi L 1988. Three interesting nematodes from the fish Parupeneus indicus (Mullidae, Perciformes) of the Indian Ocean, including a new species, Ascarophis parupenei $\mathrm{sp}$. n. (Habronematoidea). Folia Parasitol 35: 47-57.

Muñoz G, George-Nascimento M 2001. Pseudascarophis genypteri n. sp. (Nematoda: Cystidicolidae) parasite from the red ling Genipterus chilensis off Chile. J Parasitol 87: 1106-1111.

Solov'eva GF 1996. Pseudascarophis tropica n. sp. (Nematoda: Spirurina), a parasite of South China Sea fishes. Parazitologiia 25: 556-558. 